\title{
The Atmospheric River Threat to Antarctic Peninsula Ice-Shelf Stability
}

Jonathan Wille ( $\sim$ Jonathan.Wille@univ-grenoble-alpes.fr)

Institut des Géosciences de l'Environnement https://orcid.org/0000-0002-3918-5204

Vincent Favier

Institut des Géosciences de l'Environnement https://orcid.org/0000-0001-6024-9498

Nicolas Jourdain

Institut des Géosciences de l'Environnement

Christoph Kittel

University of Liège https://orcid.org/0000-0001-6586-9784

Jenny Turton

Friedrich-Alexander University

Cecilie Agosta

CEA-CNRS-UVSQ, Université Paris-Saclay https://orcid.org/0000-0003-4091-1653

Irina Gorodetskaya

University of Aveiro

Ghislain Picard

Institut des Géosciences de l'Environnement

Francis Codron

LOCEAN, Sorbonne Université https://orcid.org/0000-0001-7038-6189

Charles Amory

Institut des Géosciences de l'Environnement

Xavier Fettweis

University of Liège

Juliette Blanchet

Institut des Géosciences de l'Environnement

Vincent Jomelli

CEREGE, CNRS, Aix-en-Provence

\section{Article}

Keywords: atmospheric river threat, Antarctic Peninsula, ice-shelf stability, disintegration, detection algorithm, ice, sea-level

Posted Date: September 3rd, 2021

DOl: https://doi.org/10.21203/rs.3.rs-828007/v1

License: @ (i) This work is licensed under a Creative Commons Attribution 4.0 International License. Read Full License

Version of Record: A version of this preprint was published at Communications Earth \&amp; Environment on April 14th, 2022. See the published version at https://doi.org/10.1038/s43247-022-00422-9. 


\section{Abstract}

The disintegration of the ice shelves along the Antarctic Peninsula have spurred much discussion on the various processes leading to their eventual dramatic collapse, but without a consensus on an atmospheric forcing that could connect these processes. Here, using an atmospheric river (AR) detection algorithm along with a regional climate model and satellite observations, we show that particularly intense ARs have a $40 \%$ probability of inducing extreme events of temperature, surface melt, sea-ice disintegration, or large swells; all processes proven to induce ice-shelf destabilization. This was observed during the collapses of the Larsen A, B, and overall, $60 \%$ of calving events triggered by ARs from 2000-2020. The loss of the buttressing effect from these ice shelves leads to further continental ice loss and subsequent sea-level rise. Understanding how ARs connect various disparate processes cited in iceshelf collapse theories is essential for identifying other at-risk ice shelves like the Larsen C.

\section{Introduction}

In the past 30 years, the large and dramatic collapses of the Larsen A, Larsen B, along with other major ice shelves along the Antarctic Peninsula (AP) raised fears for the fate of other ice shelves controlling the outgoing continental ice. The associated loss of the buttressing effect from ice shelves and consequent acceleration of continental ice loss makes a critical contribution to sea-level rise ${ }^{1}$, while global warming could push the Antarctic ice shelves beyond a stability threshold during the 21 st century ${ }^{2-4}$.

Among the many preconditioning processes of ice shelf collapses, that is any event that pushes the ice shelf closer to collapse, atmospheric forcings are seemingly considered as disparate sources of ice-shelf weakening compared to non-atmospheric related processes ${ }^{5-9}$. Intense surface melting, generally associated with downsloping foehn winds descending over the leeward Larsen ice shelves ${ }^{10,11}$, can drive firn air depletion allowing crevasses to later be filled with water generating a hydrostatic pressure in a process known as hydrofracturing ${ }^{12}$. Speed limits on hydrofracture-induced ice shelf disintegration postulates that collapse occurs when a large surface area of the ice shelf experiences surface melt and melt pond formation as observed during the collapse of the Larsen B in $2002^{13}$. It is also observed that the ice shelf's final collapse can be triggered by storm generating swells causing calving on the ice-shelf front in the absence of a regional sea-ice cover ${ }^{14}$ as observed in January 1995 during the sudden collapse of the Larsen $A^{14,15}$ and again with the Larsen $B$ collapse ${ }^{14}$. The importance of these atmospheric related processes on ice shelf collapse are understood on an individual basis. However, in question is the ice shelf weakening potential if an atmospheric forcing triggered a combination of extreme events at the same time. Here we show that atmospheric rivers (ARs) aggregate seemingly disparate extreme events and are linked to ice-shelf collapse via melt-induced hydrofracturing and swell-induced strain from sea-ice clearing.

ARs are narrow long bands of enhanced moisture fluxes originating from the mid-latitudes and sub-tropics ${ }^{16}$. They have been associated with particular instances of high temperature, moisture, and wind speed in the lower troposphere ${ }^{17-19}$ along with sometimes cooccurring with foehn winds while causing significant melt events ${ }^{20,21}$ and being linked with instances of sea ice

decay ${ }^{22}$. However, a systematic long-term analysis of extreme events cooccurring with ARs still needs to be conducted along the AP to show their role in ice shelf weakening and the eventual initiation of ice shelf calving and disintegration events.

Here we used an AR detection algorithm previously utilized for studying Antarctic AR climatology, Antarctic ice sheet precipitation, and melt events in West Antarctica ${ }^{23}$, a polar-specialized regional climate model, Modèle Atmosphérique Régional ${ }^{24}$ (MAR), driven by ERA-5, and a series of satellite observations (see Methods) to retrieve calving events, surface melt occurrences, swell heights, and sea ice extent around the AP. We analyze the link between ARs and the Larsen A and B ice shelf calving and collapses and the major influence of $A R$ on the processes behind ice-shelf weakening (i.e., extreme temperature, surface melt, runoff, melt pond formation, sea-ice removal, ocean swell and sea-level height-induced ice shelf flexure, and iceberg calving). Particularly we address whether intense ARs can generate a combination of extreme events and thus potentially trigger an ice-shelf collapse.

\section{Materials And Methods}

\section{The atmospheric river detection algorithm}

The AR detection algorithm used for this study is the same version presented in Wille et al. (2021) which presented a climatology of ARs across Antarctica ${ }^{23}$. This version of the algorithm has two detection schemes based on integrated water vapor (IWV) and the v- 
component of the integrated vapor transport (vIVT). In both schemes, the algorithm scans 3-hourly IWV and vIVT fields from $37.5^{\circ}$ $\mathrm{S}-80^{\circ} \mathrm{S}$ for values within the 98th percentile of all monthly climatological values defined from 1980- March 2020. If contiguous grid cells in the meridional direction satisfy this condition and extend at least 20 degrees in the meridional direction, then the shape is flagged as an AR. If any grid cell in the AR shape intersects with the mask of the Antarctic Peninsula shown in Fig. 1e, then the date and the maximum IVT within the AR mask are recorded.

$$
\begin{array}{cc}
I W V=-\frac{1}{g} \int_{\text {surface }}^{\text {top }} & q d p(1) \\
v I V T=-\frac{1}{g} \int_{\text {surface }}^{\text {top }} & q v d p(2)
\end{array}
$$

Here IWV $\left(\mathrm{kg} \mathrm{m}^{-2}\right)$ and VIVT $\left(\mathrm{kg} \mathrm{m}^{-1} \mathrm{~s}^{-1}\right)$ are calculated based on the specific humidity, $q\left(\mathrm{~kg} \mathrm{~kg}^{-1}\right),{ }^{g}\left(\mathrm{~m} \mathrm{~s}^{-2}\right)$ gravitational acceleration,v meridional wind velocity $\left(\mathrm{m} \mathrm{s}^{-1}\right)$, and $p$ atmospheric pressure $(\mathrm{hPa})$. Using both an IWV and vIVT scheme in this study captures some of the variability between different approaches of AR detection. The IWV scheme is slightly advantageous for studying the effects of ARs on surface melting since excessive IWV leads to the development of mixed phase clouds containing anomalously high liquid and ice water paths with higher radiative fluxes ${ }^{20}$. However, the meridional wind component in the vIVT scheme captures some of the dynamical processes that lead to foehn wind generation and subsequent sensible heat fluxes on the AP ice shelves. While the vIVT generally detects more ARs than the IWV scheme, controlling for maximum IVT upon landfall greatly reduces this disparity and shows that differences in AR detection is mainly influenced by the depiction of weaker ARs (Fig. 1b and $1 d)$.

The AR detection algorithm in this study was configured to be included in the Atmospheric River Tracking Method Intercomparison Project ${ }^{16}$ (ARTMIP). This entails running the detection algorithm on fields from the Modern-Era Retrospective analysis for Research and Applications, Version $2{ }^{61}$ (MERRA-2) on all pressure levels and outputting the AR shapes in binary form. For the sake of comparison, the AR detection algorithm was also run on ERA-5 IWV and VIVT fields on a $1 \times 1$ degree grid. The previous studies of ARs over Antarctica confirmed that the AR detection frequency is similar amongst various modern reanalysis products 20,23 and it is confirmed again in this study between MERRA-2 and ERA-5 (Fig. 1). The analyzes presented in this manuscript were primarily computed using the VIVT scheme applied to MERRA-2 reanalysis unless explicitly stated otherwise. AR intensity is measured through different metrics depending on the variable being analyzed. Instantaneous intensity which is useful for measuring a corresponding instantaneous variable (i.e., 3-hourly temperature extreme, melt rate, and runoff rate seen in Fig. 3, Fig. 5, Fig. 7) is measured from the maximum IVT value simulated within the shape of the AR over the AP domain (see Fig. 1e). Throughout the manuscript, a maximum IVT threshold above $400 \mathrm{~kg} \mathrm{~m}^{-1} \mathrm{~s}^{-1}$ is used to describe intense ARs which also reduces the spread in AR frequency estimation amongst the MERRA-2, ERA-5, vIVT, and IWV detection schemes (Fig. 1). Cumulative intensity which is useful for measuring the cumulative effects of an AR landfall (i.e., iceberg calving frequency seen in Fig. $6 \mathrm{~b}$ and the relationship between annual cumulative AR intensity and melt/runoff seen in Supplementary Fig. 10) is the summation of maximum IVT over the course of a distinct AR landfall event thus incorporating the duration and IVT strength of the storm. Daily cumulative intensity is like the cumulative intensity except we make the summation of maximum IVT for daily periods when an AR landfall is detected. This is used for testing the probability of an extreme state (i.e., temperature extreme, melt extreme, runoff extreme, two-day sea ice removal, high swell seen in Fig. 6a)

\section{Regional climate model and reanalysis datasets}

MAR is a regional climate model specifically designed for simulating polar climate 24,62 . MAR atmospheric dynamics are based on the hydrostatic approximation of the primitive equations ${ }^{63}$. The exchanges between the atmospheric part of MAR and the surface are handled by the complex energy-balance snow model SISVAT ${ }^{64}$, based on CROCUS ${ }^{65}$ that explicitly simulates 30 layers resolving the 20 first meters of snow or ice. The surface module notably represents percolation of meltwater and its retention into the snowpack. Runoff occurs when the snowpack can no longer absorb additional liquid water (i.e., snowpack water content exceeding $5 \%$ or surface liquid water over bare ice or an ice-lense layer). MARv3.11 was run at a resolution of $7.5 \mathrm{~km}$ and was forced by 876-hourly outputs of the latest ERA5 reanalysis between 1979 and March 2020. The first year was discarded as spin-up. MAR evaluation 
MAR has been thoroughly compared to observation from weather stations, satellite melt extent, AWS-forced melt estimates and SMB measurements over the Antarctic ice sheet ${ }^{24,66-68}$ and more specifically over the Peninsula ${ }^{11,69}$. The model is also abundantly evaluated over the Greenland ice sheet ${ }^{70}$ (e.g. Fettweis et al. 2020). The ability of MAR to represent melting over Antarctic ice shelves has already been discussed in Datta et al., $2018^{69} ; 2019^{71}$ and Donat-Magnin et al. $2020^{67}$, so we present here a short comparison with AWS observations and melt estimates. MAR correctly represents the variation in near-surface temperature (Supplementary Fig. 13a) with a centered RMSE (i.e., RMSE where we removed systematic biases attributed to elevation difference) of $2.6^{\circ} \mathrm{C}$ over the ice shelves and $3.2^{\circ} \mathrm{C}$ over the grounded ice. The comparison also reveals a mean negative bias. MAR tends to slightly underestimate the high (positive) temperatures while overestimating the low temperatures that can be found over higher elevations or in winter. Despite the high resolution of these simulations $(7.5 \mathrm{~km})$, the altitude of pixels relating to AWS near the margins is overestimated in MAR by slightly less than 100 meters, likely explaining a significant part of the negative bias over low-elevation areas and ice shelves. There is no direct observation of melt, so we compared MAR to melt estimates using an AWS-forced snow model ${ }^{72}$. Only AWS locations whose elevation difference with MAR does not exceed $250 \mathrm{~m}$ were selected. This comparison (Supplementary Fig. 13b) reveals that the model correctly reproduces the annual surface melt at the AWS situations (located on the Larsen C and Scar Inlet of Larsen B), except in 2017 at Larsen C West where MAR overestimated melt.

\section{Sea ice and wave simulations}

ERA-5 includes a two-dimensional wave model coupled to the atmosphere. It solves the wave energy balance equation, using wave spectra with 24 directions and 30 frequencies, and includes assimilation of altimeter wave height ${ }^{73}$. Although advanced methods to represent wave-sea ice interactions have been tested at the European Centre for Medium-Range Weather Forecasts ${ }^{73}$ (ECMWF), their representation in ERA-5 is very simple: the wave energy is set to zero where the sea ice concentration exceeds $30 \%$, and there is no wave attenuation for lower concentrations (Bidlot, J. R., personal communication).

\section{Satellite observations}

MODIS-Terra Aqua images were acquired at the (https://worldview.earthdata.nasa.gov) over the entire period of availability, from the end of August to the beginning of April from between February 25, 2000 and April 28, 2020. The worldview interface allows comparing images between two different dates, making it possible to retrieve the exact occurrence of the main calving events and collapses of the ice shelves when cloud interference is limited. Since the foehn effect induces a reduction of the cloud cover at the east of the Antarctic Peninsula, it was possible to retrieve the approximate occurrence of most events of the Larsen A, B and C ice shelves. Accurate examination of images before winter (end of April) and after winter (beginning of August) allowed us to verify that most large ice-shelf calving/collapse on the Larsen ice shelves occurred during the summer in the 20 years of observation (see images in supplementary material for examples). It is important to note that the dates we link with calving/collapse events are subject to uncertainty based on when sky conditions allow us to observe these events.

Since daily MODIS images were not available before February 25, 2000, collapses and large calving events occurring before this date were not considered in our analysis. Nevertheless, we analyzed the well documented collapse of the Larsen A ice shelf ${ }^{15}$ using AVHRR satellite images available on the National Snow and Ice Date Center (NSIDC) website ${ }^{74}$ surrounding the date of the Larsen A collapse.

Winter calving events were not retrieved with the same accuracy because even though thermal bands could be used during polar night, this imagery technique is more sensitive to cloud cover (even thin cloud are opaque). This lowers the resolution even given favorable cloud cover, thus making the acquisition of data at a daily time scale not straightforward. Even if we present the Larsen $\mathrm{C}$ calving event of July $10-12,2017$, we did not consider this event in the final statistics. This prompted us to consider the iceberg retrieval database from Stuart and Long, $2011^{75}$. Here we extracted the initial location of icebergs around the Larsen ice shelves, but difficulty was encountered in tracing with confidence the origin of these icebergs to a given ice-shelf because the first detection of an iceberg can occur days after calving and its position can be far from its parent ice-shelf. Nevertheless, the information of proximity with an ice shelf provides some hints on calving in the Larsen area. In the latter database, winter occurrences are also largely less frequent.

Similar examination was more limited over the Wilkins ice shelf because cloud cover is generally denser, so collapses and calving events are generally observed a few days after their occurrence. Moreover, contrary to the eastern side, several large events that

Page $4 / 21$ 
occurred in the darker autumn and winter periods were not visible in MODIS datasets. This made the attribution of ARs to calving occurrences more difficult on the western side of the AP.

Surface melt surface anomalies over the Larsen ice shelves were also retrieved between October 1 and March 31 every year over

1979-2020 ${ }^{76}$. A series of microwave radiometer observations (namely Scanning Multichannel Microwave Radiometer (SMMR), the Special Sensor Microwave/Imager (SSM/I) and Special Sensor Microwave Imager/Sounder (SSMIS)) were processed to test our conclusions on AR impact on snow melt (see Supplementary Fig. 6). First, a climatology of daily melt surface extent based on mean values for each Julian day mean was computed over the full 41 year-long period. The daily melt anomalies were computed by comparison with this climatology and compared with AR occurrences. Data obtained before 1993 must be considered with caution, in particular with summer 1987-88 29

Finally, to complement our analysis on the relationship between melt pond observations and AR activity obtained using the MODIS image interpretation by Hubbard et al. $2016^{32}$, we also studied the Landsat8 image database ${ }^{77}$ (Moussavi et al., 2020), used by Banwell et al., $2021^{29}$. Information on lake extent on the Larsen ice shelves were retrieved and merged over periods of 16 days (corresponding to the Landsat revisit time). Far larger melt pond areas were usually observed at the end of February and in March, but after a comparison with Sentinel 2 images over the same periods, we concluded that this very likely reflects artefacts resulting from the misclassification of scattered cloud shadows as lakes by the algorithm Moussavi et al. $2020{ }^{77}$. This issue is more prominent at the end of the summer when the zenith angle is high and the shadows of scattered clouds are far away from the cloud vertical, maximizing the areas of misclassification. This artefact impedes an accurate estimation of melt pond areas in February and March, i.e., when melt ponds should be most impactful on hydrofracturing processes. While improving the algorithm to address this issue seems worthwhile, it is beyond the scope of this study as it would require reprocessing the full Landsat8 archive on Larsen ice shelves.

\section{Statistical significance of AR-extreme event co-occurrences}

To confirm that AR and collapses were not independent, we considered various 1000 random selections of dates between August and March from 2000-2020, and we find that the probability of having an AR within the 5 preceding days is $24.5 \%$. If ARs and collapses were independent, then the number of collapses (among the 21) that would occur after ARs (within the 5 preceding days) would follow a binomial distribution with parameters $n=20$ and a probability $p=0.245$. Considering that 13 out of 21 events cooccurred with an AR within the 5 preceding days, this leads to a $p$-value of $p=5.310^{-5}$. In other words, there is less than $1 / 1000$ chance to experience $13 \mathrm{AR}$ events or more if AR and collapses were independent. We applied the same approach to retrieve the level of significance of co-occurrences between AR and extreme temperature, melt, runoff, and swell height. For composite ARrelated rainfall and AR-related two-day sea-ice change, we tested the equality of the means of AR days and non-AR days with a Student's t-test (see main text for results).

\section{Results}

Ice shelf calving and collapse cooccurrences with ARs

To examine cooccurrences between AR landfalls and iceberg calving along the Larsen ice shelves, we produced a climatology of AR landfalls along the AP from 1989-2020 using output from the AR detection algorithm with input from MERRA-2 reanalysis where instantaneous intensity is measured by integrated vapor transport (IVT) (see Fig. 1 and Methods for AR annual frequency and specifics on the AR detection algorithm respectively). We also examined calving and collapse events along Larsen A, B and C (between $64.5^{\circ} \mathrm{S}$ and $68.5^{\circ} \mathrm{S}$ ) using MODIS-Terra and Aqua visible imagery from August-March 2000-2020. We observe that AR landfalls along the AP are slightly more frequent than other coastal regions of the continent ${ }^{23}$ (around 1-5 landfalls per austral summer, i.e., between December-March) and occur during strong downstream blocking conditions thus agreeing with previous Antarctic AR climatology assessments ${ }^{20,23}$. We found 21 major calving and collapse events between 2000-2020, all occurring before a decrease in AR activity after 2010. 13 out of the 21 calving events were preceded by an AR landfall within 5 days prior (The Larsen C calving in July 2017 is not considered here as it could not be retrieved during austral winter using MODIS although an AR was detected within 5 days prior of the supposed calving date; see Supplementary Data 1). A statistical analysis based on thousands of artificial AR occurrences at randomly selected dates between August and March from 2000-2020 confirms that ARs

Page 5/21 
and these calving/collapse events were not independent at $p=5.310^{-5}$. The number of co-occurrences decrease if we consider AR landfalls within less than 5 days prior to calving events, but the co-occurrences are still statistically significant (except if we only consider cooccurrence on the same date) confirming that these ARs and calving/collapse events were not independent. In contrast with high swell events (swells within the $85^{\text {th }}$ percentile of height), ARs are more likely to cause a calving/collapse event with only 9 out of 21 events cooccurring with 5 days prior of a high swell.

As an example of AR impacts on ice-shelf weakening processes, the intense AR that made landfall from January 24-26, 2008, is particularly striking. MODIS satellite imagery shows that this historically intense AR detection (IVT $962 \mathrm{~kg} \mathrm{~m}^{-1} \mathrm{~s}^{-1}$, third highest intensity of all AR landfalls in our AR climatology) disintegrated and fragmented nearly all the land fast ice in the Larsen A and $B$ embayments and generated $6.3 \mathrm{Gt}(7.2 \mathrm{Gt}$ ) of runoff (meltwater) simulated by MAR likely leading to a calving event 6 days later (Fig. 2). This calving event (not included in our 13 cooccurring calving events) led to a $11 \mathrm{~km}$ retreat of the eastern region of the remnant Larsen B (named Scar Inlet ice shelf) ${ }^{25}$. Other striking examples are the multiple AR events that preceded the collapse of the Larsen B in austral summer 2002 and the historically intense AR preceding the collapse of the Larsen A ice shelf and associated iceberg calving $\left(\sim 1700 \mathrm{~km}^{2}\right)$ from the Larsen B in 1995 ${ }^{15,26}$ (Supplementary Fig. 3). In all these cases, the AR generated several Gt of meltwater and runoff, large reductions of sea-ice concentrations in the Larsen embayment, strong winds, and large swells (Table 1, Supplementary Fig. 3, see the supplementary materials for more examples of AR landfalls and their associated impacts on processes connected to ice-shelf weakening).

\section{Atmospheric river impacts on processes detrimental to ice shelf stability}

Hereafter, we demonstrate that ARs generate cooccurring extreme temperature, melt, runoff, and swell events, by analyzing values within the 99.9th percentile that occurred 24 hours before and after an AR landfall. Given AR landfall frequency on the AP, a result above $61 \%$ of cooccurrences is significant at the level of $1 \%$. We also analyzed the rainfall percentage and composite sea-ice fraction change associated with ARs.

First, ARs are observed to strongly affect extreme high temperature events. Figure 3a shows that nearly all occurrences of $2 \mathrm{~m}$ air temperatures above the 99.9th percentile simulated by MAR (61-100\% out of $\sim 40$ at a 3-hour time step) and of most temperatures above the 99th percentile (61-70\% out of 280 occurrences at a 3-hour time step) occur within 24 hours before and after an AR landfall (Supplementary Figs. 4a and $4 \mathrm{~b}$ ). In fact, the previous two Antarctic temperature records recorded at Esperanza Base in March 2015 and in February 2020 coincided with intense AR events that triggered foehn wind events ${ }^{21,27}$ (see Supplementary Fig. 5). Higher nighttime temperatures from enhanced downward longwave radiation were also observed meaning that the melted water during ARs is less likely to refreeze in the firn and thus contribute to runoff ${ }^{28}$.

Second, we observe $\left(>61 \%\right.$ ) of melt rates at or above the $99.9^{\text {th }}$ percentile along portions of the Larsen and Wilkins ice shelves and higher percentages on the glaciers in the mountainous regions occurred within the 24-hour period surrounding AR landfalls (Fig. 3c; Supplementary Figs. 4c, 4d). To complement our analysis of surface melt and the overall presence of liquid water on the snow surface based on MAR simulated results, we used passive microwave radiometer data from Scanning Multichannel Microwave Radiometer (SMMR) and Special Sensor Microwave/Imager (SSM/I). Results show that ARs typically engender neutral to largely positive melt extent anomalies in daily climatological melt extents along the Larsen $C$ ice shelf especially outside of the peak firn saturation months of February and March (Supplementary Fig. 6). During these months, the presence of a saturated firn can obscure the occurrences of new melt detected by passive microwave remote sensing ${ }^{29}$. Still, from October to March, we observe that two thirds of AR landfalls were associated with positive melt anomalies, suggesting that ARs generally produce anomalously widespread melt.

Third, related with melt water, rainfall events lead to periods of extremely high rates of firn saturation and runoff ${ }^{30}$. Runoff here refers to liquid water beyond the saturation point of the snowpack that does not necessarily drain into the ocean and could remain on the ice shelf. From 40 to $60 \%$ of total annual rainfall along the Larsen and Wilkins ice shelves are linked to ARs (Fig. 3b) whereas ARs days also produced a statistically significant higher amount of rainfall than non-AR days ( $p$-value $<0.0025)$. Runoff rates thus show similar relationships to AR activity as melt rates, the only difference being that runoff is predominately constrained to the lower-elevation ice shelves (Fig. 3d, Supplementary Figs. 4e and 4f). High runoff values, produced by melting and rainfall when the firn is already saturated with liquid water, are detrimental for ice-shelf stability ${ }^{31}$. Indeed, these high melt and runoff rates lead to 
melt pond formation as demonstrated by the significant correlation between melt pond observations from MODIS and summer AR occurrences $^{32}$ (Supplementary Fig. 7).

Fourth, beyond processes related with melt and hydrofracturing, ARs are also observed to induce a rapid clearing of sea ice along the ice shelf fronts allowing cooccurring anomalously large swells to reach the ice-shelf and apply strain ${ }^{14}$. This swellinduced stress leads to the calving of large icebergs and could result in the retreat of the compressive arch like what occurred on the Larsen B in $20022^{14,33}$. On average, the strong ARs (those with integrated vapor transport (IVT) $>400 \mathrm{~kg} \mathrm{~m}^{-1} \mathrm{~s}^{-1}$ upon landfall) cause a two-day sea-ice fraction decrease of nearly $10 \%$ (i.e. about 5 sigma of sea-ice variation in this region) on the northern edge of the Larsen A and B embayment (Fig. 3e). This average sea-ice fraction decrease is slightly larger when considering four-day sea-ice change. Nearly all large and rapid sea-ice disintegration events of around a 10\% decrease over two days east of the Larsen ice shelves (in the region labelled EAP) co-occurred with AR landfalls (Supplementary Fig. 8). The average two-day sea-ice change during intense AR days in this region (2.5\% reduction) is statistically significantly higher than non-AR days $(0.1 \%$ increase; $\mathrm{p}$-value < 0.0025). West of the AP, the average sea-ice decline in response to ARs is smaller, yet still notable around the Wilkins ice shelf and along the sea-ice front in the Bellingshausen Sea like during 2002 and 2005 when AR activity was elevated ${ }^{29,31}$ (Fig. 1, Fig. 3e). At the same time, the winds found near the surface during an AR within the low-level jet are often extreme as noticed during the AR landfall coincident with the collapse of the Larsen A in 1995 (Supplementary Fig. 9a) and can lead to significant swell heights. When sea ice is depleted east of the Larsen ice shelves, $61-80 \%$ of swells in the $99.9^{\text {th }}$ percentile of height co-occurred with an AR landfall (Fig. 3f).

Consequently, AR landfalls prompt a state of high stress on the ice shelves through the combination of surface melt induced melt pond formation leading to hydrofracturing and wave strain along the ice shelf front. The tendency of ARs to create widespread melt pond formation makes them possible precursors of ice shelf collapse via hydrofracturing cascades like what was observed on the Larsen $B$ in $2002^{13}$. This combined with wind stress and radiative forcing leading to sea-ice clearing thus allowing swells to apply strain along the ice shelf fronts 14,22 makes ARs a unique forcing of ice-shelf weakening. Figure 4 provides a visualization summarizing all the aforementioned processes during AR landfalls that are linked to ice shelf weakening. The AR example in the schematic showcases an AR making landfall perpendicular to the ice shelf and generating a foehn wind. However, there are cases of ARs approaching the AP from different angles that do not result in foehn but still generate all the other illustrated effects.

We studied other possible connections between ARs and ice-shelf weaking and did not find conclusive evidence for a direct relationship between AR activity and ice-shelf basal melting, one of the long-term precursors of ice shelf collapse ${ }^{34}$. Indeed, looking at ocean hindcasts from 1979-2018 ${ }^{35}$, we did not find any significant correlation between either yearly AR frequency or yearly cumulative maximum IVT and either the ocean temperature at the depth of the ice-shelf drafts or Ekman pumping (a driver of basal ice-shelf melt variations according to Etourneau et al., 2019, ${ }^{36}$ near Larsen or Wilkins ice shelves. For a single weather event, Francis et al. (2021) showed that a significant sea surface height (SSH) anomaly in front of the Amery ice shelf may have contributed to trigger a calving event ${ }^{37}$. However, looking at SSH anomalies in the global ocean simulations from 1979-2015 produced by Merino et al. $2018{ }^{35}$, we did not identify any significant SSH anomalies associated with ARs on both sides of the AP.

\section{Characterizing cumulative impacts of atmospheric river events}

The previously described ice-shelf weakening processes associated with AR landfalls become more impactful and likely as the AR intensity increases as a function of maximum IVT upon landfall. In fact, these most intense ARs often have the greatest surface melt potential. The relationship between maximum IVT upon landfall and both total melt and runoff along the Larsen ice shelves is

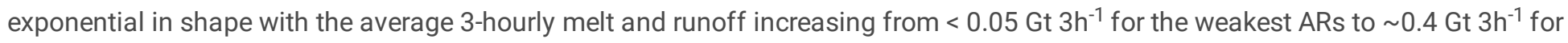
the strongest (Fig. 5; melt and runoff is calculated in the areas highlighted in Fig. 5c). These most extreme ARs (IVT $>800 \mathrm{~kg} \mathrm{~m}^{-1} \mathrm{~s}^{-1}$ ) only occur around once every five years but have the capability to alter the cryosphere dramatically and quickly like observed in the January 2008 example (Fig. 2), the collapse of the Larsen A in 1995 (Supplementary Fig. 3), and in the March 2015 melt event/temperature record described in Bozkurt et al., $2018^{21}$. When AR strength and impacts are characterized by considering the maximum IVT upon landfall and the landfall duration, like the scale used to classify ARs in western North America ${ }^{38}$, consistent relationships between AR intensity and impacts emerge. This includes a significant correlation between annual AR cumulative intensity and annual melt/runoff across portions of the Larsen ice shelves (Supplementary Fig. 10). 
As the cumulative maximum IVT of the AR increases, the more likely a temperature extreme, melting extreme, sea ice disintegration or high swell event occurs. This is visible in Figure 6a, where AR intensity is assessed by summing the maximum IVT values throughout the day when an AR is detected. Taken as a whole, all these events represent a physical state which promotes ice shelf weakening as confirmed by the cooccurring calving and even collapse events with AR landfalls. For the most intense ARs at landfall, there is a nearly $20 \%$ probability of a daily temperature, melt, or runoff extreme occurring over at least half the lower elevation portion of the northern AP (blue line and area; see Fig. $6 \mathrm{c}$ for domain). There is an increase in probability when the same calculation is repeated but with the added option of a significant sea-ice decline occurring (up to $40 \%$, red line and area), and with the option of a high swell event east of the AP (green line and area).

We also analyzed if iceberg calving and ice-shelf collapse events were related with AR cumulative intensity within 5 days after the AR event. When defining AR intensity using the cumulative maximum IVT throughout a discrete continuous AR landfall event, we find around $60 \%$ of calving/collapse events (13 out of 21 total events over August-March 2000-2020 plus the collapse of the Larsen A in 1995 and the calving event from the Larsen C in July 2017), occurred when an AR with at least a cumulative IVT value of 500 $\mathrm{kg} \mathrm{m}^{-1} \mathrm{~s}^{-1}$ was detected within 5 days prior. Although, that percentage progressively decreases as the IVT threshold increases (see Methods for details on the statistical significance of the lag between AR and calving). This suggests that calving requires neither a large trigger nor large swell heights once hydrofracturing and other weakening processes have already weakened the stability of the ice shelf front. However, the major collapses of the Larsen A and B were preceded by intense ARs like the early January-February 2002 AR that caused widespread melt pond formation across the Larsen B and contributed to large swell heights (Table 1, Supplementary Fig. 2). Even more significant in terms of summer AR activity, the summer 2002 had the second highest IVT over 1980-2020, coinciding with exceptional sea-ice-free conditions around the AP and with large wave-induced flexure on the ice shelves ${ }^{14}$ (Table 1).

\section{Physical particularities of AR events}

When ARs make landfall perpendicular to the mountains of the AP, their large moisture transport typically engenders a large latent heat release. These are ideal conditions for foehn winds, which are commonly proposed to trigger of intense surface melt along the leeward AP ice shelves $20,21,27,39-41$. However, the enhanced moisture transport also triggers melt through clouds containing anomalously high liquid and ice water content resulting in high downward longwave radiation ${ }^{20}$. Thus, it is important to analyze the differences between these distinct phenomena, ARs and foehn winds.

To compare AR and foehn frequency and surface melt potential, we compared AR landfalls events against instances of foehn winds detected by a dedicated algorithm ${ }^{11}$ (see Turton et al., 2018), which is based on relative humidity observations from six automatic weather stations (AWSs) and model output from the Antarctic Mesoscale Prediction System (AMPS). From 2009-2012, the amount of AR events per year to occur within 24 hours of a foehn detection ranged from 17\%-63\%. (see Supplementary Table 1), and these percentages increase when considering only intense ARs (IVT $>400 \mathrm{~kg} \mathrm{~m}^{-1} \mathrm{~s}^{-1}$ upon landfall). The foehn events that are related to ARs appear to have a greater duration and extent over the ice shelves than non-AR related foehn events. Indeed, $43 \%$ of all foehn events detected at more than four or more AWSs are associated with ARs (compared to $22 \%$ only detected at one station) and $60 \%$ of foehn events lasting more than 3 days are associated with ARs (compared to $23 \%$ only lasting 0-2 days). The greater impact area during AR-related foehn events can be explained by the higher windward flow velocity ${ }^{10}$. ARs with their associated high wind speed are more likely to create a linear flow across the ice shelves, mechanically mixing down warm air aloft and transporting sensible heat to the surface. Weaker foehn events are typically associated with nonlinear flow over the mountains which results in hydraulic jumps shortly after descending thus limiting the warming extent over the ice shelf ${ }^{10}$.

Thus, standalone foehn events are associated with less intense and widespread melt across the Larsen ice shelves. This is further observed with intense ARs (IVT > $400 \mathrm{~kg} \mathrm{~m}^{-1} \mathrm{~s}^{-1}$ upon landfall). If we compare all ARs and foehn events from 2009-2012 using MAR, ARs generated smaller positive $2 \mathrm{~m}$ temperature anomalies along the base of the leeward AP mountains, but higher anomalies across the rest of the AP (Fig. 7a), with greater melt along regions in the northern AP (Fig. 7b). Higher melt is explained by ARs producing greater downward longwave radiation flux anomalies (associated with higher cloud liquid/ice water contents) (Fig. 7c and 7d). We also see that ARs enhance the melting potential of the foehn when comparing foehn events co-occurring with an AR landfall against all foehn events. Supplementary Fig. 11). 


\section{Summary And Discussion}

Here, we demonstrated that a relationship exists between AR intensity (measured by duration and maximum IVT upon landfall) and the likelihood of an extreme state of conditions occurring on the northern AP (i.e., temperature extreme, melt extreme, sea-ice disintegration, swells). Strong ARs were precursors for more than $60 \%$ of the major calving events of the Larsen A and Larsen B ice shelves since 2000 and preluded their main collapses. On the Wilkins ice shelf, the relationship with ARs and calving is less clear. ARs induce extreme temperature and melt states on the Wilkins ice shelf, but do not appear immediately related to any calving or disintegration events. The prevalence of perennial firn aquifers on the Wilkins ice shelf may explain the disparity between AR occurrences and calving/collapse events since it can delay or reduce runoff 12,42,43. The occurrence of downsloping foehn winds that adiabatically warms and causes isentropic drawdown triggering surface melting along the leeward ice shelves ${ }^{10,11,41}$ could also partly justify a higher link between ARs and calving/collapses along the eastern side of the AP. However, standalone foehn events are insufficient to justify the ice-shelf weakening, unlike ARs which are synoptic-scale phenomena connected to multiple processes with ice-shelf weakening consequences like sea-ice clearing and swell generation east of the AP.

Nevertheless, the processes that lead to the final collapse of an ice shelf are complex, not fully understood, and likely go beyond the influence of an event that is temporally minuscule in comparison to the age of the ice shelf and thus requires further exploration. Still, the broader implication here is that ice dynamic/ice sheet stability models need to account for short term extremes in atmospheric behavior beyond changes in the mean signal like understanding how an ice shelf responds to an AR event.

Although ARs are an ever-present feature of the AP climate system that cause short-term conditions which are consequential to iceshelf stability, their effects have mostly been noticed during the relatively recent period of warmth in the late 20th century 44 . Temperature extremes along the AP also reached a maximum during this time ${ }^{45}$, but then decreased throughout the 21 st century which followed a decreasing trend in AR activity (Fig. 1). This implies that AR trends and impacts follow the same patterns as average temperature trends and ARs only become detrimental above a certain average temperature threshold. Indeed, the southeasterly flow responsible for warm air advection over the AP is also the observed flow during AR events meaning ARs act as extremes within an already warm state. While atmospheric blocking downstream of the AP and the positive phase of the Southern Annular Mode (SAM) are significantly correlated with AR activity ${ }^{23}$, it is currently unclear what conditions lead to the initial tropical moisture export. Further research into regional sea surface temperature anomalies and other teleconnections may address this issue ${ }^{18,46}$.

\section{Are other Antarctic ice shelves in trouble?}

After a record melt year along the AP ice shelves in 2019/2020 that brought an end to the decreasing melt trend that started in 1999/2000 29,47, it appears the remaining AP ice shelves might be entering a new phase of vulnerability from ARs. Attention is now on the Larsen $C$ ice shelf after a giant iceberg calving event on July 10-12, 2017. This event has been attributed to basal melting from subsurface ocean warming $34,48,49$. Curiously, a relatively strong winter AR on July 5-6, 2017, may have applied a wind stress prior to the calving, but the impacts of winter ARs on ice-shelf stability are unclear as they generally produce lower melt values compared to the summer melt season. Other calving events on the Larsen C like in January and February 2005 are more directly related to ARs (Supplementary Fig. 12). If the Larsen C recedes beyond its compressive arch or the passive shelf ice decays ${ }^{33,50}$, the shelf would possibly become vulnerable to collapse from further surface melting and hydrofracturing ${ }^{51}$. With the predictions of an extended melt season ${ }^{52}$, a southward migration of surface and subsurface melting conditions ${ }^{36,53}$, and an increase in AR frequency and intensity across the Southern Ocean in future global warming scenarios ${ }^{54}$, the Larsen $\mathrm{C}$ may experience more widespread melt and become increasingly vulnerable to future changes in AR behavior. Tracking ARs by measuring IVT and duration is a useful complementary tool in assessing the future ice shelf disintegration risk of the Larsen C.

Increasing temperatures may put other ice shelves with similar vulnerabilities to foehn winds, hydrofracturing, and swell-induced strain at risk of collapse ${ }^{2,51}$. It is important to identify which ice-shelves may become threatened by AR-related extreme processes in warming scenarios ${ }^{2}$. Previous research cataloging which ice shelves are susceptible hydrofracturing ${ }^{51}$, identifying a foehn melt mechanism on the Ross Ice Shelf ${ }^{55,56}$, and ice shelves that experience calving from ocean swells ${ }^{37,57,58}$ are important examples of 
this. In addition, analyzing AR effects on Antarctic ice shelves using various other AR detection algorithms could quantify the range of uncertainty in ice-shelf risk introduced by the choice in AR detection $16,59,60$.

\section{Declarations}

\section{Acknowledgments}

This study is part of the PhD project of J.D.W. conducted at the Université Grenoble Alpes. Particular thanks to Simon Gascoin for providing help in the MODIS images retrieval and to Alison Delhasse for her monitoring of the MAR simulations.

\section{Funding:}

We acknowledge support from the Agence Nationale de la Recherche projects ANR-20-CE01-0013 (ARCA), ANR-14-CE01-0001 (ASUMA), ANR-16-CE01-0011 (EAIIST), ANR-15-CE01-0005-01 (TROIS AS) and ANR-15-CE01-0015 (AC-AHC2). IVG thanks FCT/MCTES for the financial support to CESAM (UIDP/50017/2020 and UIDB/50017/2020) through national funds and support to project ATLACE (CIRCNA/CAC/0273/2019) funded by FEDER, through COMPETE2020 - Programa Operacional Competitividade e Internacionalização (POCI), and by national funds (OE), through FCT/MCTES. CA acknowledges support from the Fondation Albert 2 de Monaco under project Antarctic-Snow (2018-2020). Computational resources were provided by the Consortium des Équipements de Calcul Intensif (CÉCI), funded by the F.R.S.-FNRS under grant no. 2.5020.11.

\section{Author contributions:}

Conceptualization: JDW, VF

Methodology: JDW, VF, CK, JT, CA, GP, XF, CA

Formal analysis: JDW, VF, NCJ, CK, JT, IVG, FC, JB

Visualization: JDW, VF, CK, CA, IVG

Writing-original draft: JDW, VF, NCJ, CK, CA, IVG, FC, XF, CA

Writing-review \& editing: JDW, VF, NCJ, CK, JT, CA, IVG, GP, FC, XF, CA, JB, VJ

\section{Competing interests:}

Authors declare that they have no competing interests.

\section{Data and materials availability:}

The Modèle Atmosphérique Régionale (MAR) data is available from C.K (ckittel@uliege.be). MODIS-Terra Aqua images were acquired at the (https://worldview.earthdata.nasa.gov). AVHRR imagery was acquired from the NSIDC(86). The code for the AR detection algorithm discussed in this paper is available at https://doi.org/10.5281/zenodo.4009663 and the output can be downloaded from the ARTMIP database at https://www.earthsystemgrid.org/dataset/ucar.cgd.ccsm4.artmip.tier1.html.

\section{References}

1. Smith, B. et al. Pervasive ice sheet mass loss reflects competing ocean and atmosphere processes. Science $368,1239(2020)$.

2. Gilbert, E. \& Kittel, C. Surface Melt and Runoff on Antarctic Ice Shelves at $1.5^{\circ} \mathrm{C}, 2^{\circ} \mathrm{C}$, and $4^{\circ} \mathrm{C}$ of Future Warming. Geophysical Research Letters 48, e2020GL091733 (2021).

3. Edwards, T. L. et al. Projected land ice contributions to twenty-first-century sea level rise. Nature 593, 74-82 (2021).

4. Bozkurt, D., Bromwich, D. H., Carrasco, J. \& Rondanelli, R. Temperature and precipitation projections for the Antarctic Peninsula over the next two decades: contrasting global and regional climate model simulations. Climate Dynamics (2021) doi:10.1007/s00382-021-05667-2. 
5. Banwell, A. F., Willis, I. C., Macdonald, G. J., Goodsell, B. \& MacAyeal, D. R. Direct measurements of ice-shelf flexure caused by surface meltwater ponding and drainage. Nat Commun 10, 730 (2019).

6. Vieli, A., Payne, A. J., Shepherd, A. \& Du, Z. Causes of pre-collapse changes of the Larsen B ice shelf: Numerical modelling and assimilation of satellite observations. Earth and Planetary Science Letters 259, 297-306 (2007).

7. Scambos, T. et al. Ice shelf disintegration by plate bending and hydro-fracture: Satellite observations and model results of the 2008 Wilkins ice shelf break-ups. Earth and Planetary Science Letters 280, 51-60 (2009).

8. Khazendar, A., Rignot, E. \& Larour, E. Larsen B Ice Shelf rheology preceding its disintegration inferred by a control method. Geophys. Res. Lett. 34, L19503 (2007).

9. Glasser, N. F. \& Scambos, T. A. A structural glaciological analysis of the 2002 Larsen B ice-shelf collapse. J. Glaciol. 54, 3-16 (2008).

10. Elvidge, A. D., Renfrew, I. A., King, J. C., Orr, A. \& Lachlan-Cope, T. A. Foehn warming distributions in nonlinear and linear flow regimes: a focus on the Antarctic Peninsula: Foehn Warming Distributions in Nonlinear and Linear Flow Regimes. Q.J.R. Meteorol. Soc. 142, 618-631 (2016).

11. Turton, J. V., Kirchgaessner, A., Ross, A. N. \& King, J. C. The spatial distribution and temporal variability of föhn winds over the Larsen C ice shelf, Antarctica. Q.J.R. Meteorol. Soc. 144, 1169-1178 (2018).

12. Alley, K. E., Scambos, T. A., Miller, J. Z., Long, D. G. \& MacFerrin, M. Quantifying vulnerability of Antarctic ice shelves to hydrofracture using microwave scattering properties. Remote Sensing of Environment 210, $297-306$ (2018).

13. Robel, A. A. \& Banwell, A. F. A Speed Limit on Ice Shelf Collapse Through Hydrofracture. Geophys. Res. Lett. 46, 12092-12100 (2019).

14. Massom, R. A. et al. Antarctic ice shelf disintegration triggered by sea ice loss and ocean swell. Nature 558, 383-389 (2018).

15. Scambos, T. A., Hulbe, C., Fahnestock, M. \& Bohlander, J. The link between climate warming and break-up of ice shelves in the Antarctic Peninsula. J. Glaciol. 46, 516-530 (2000).

16. Rutz, J. J. et al. The Atmospheric River Tracking Method Intercomparison Project (ARTMIP): Quantifying Uncertainties in Atmospheric River Climatology. Journal of Geophysical Research: Atmospheres 124, 13777-13802 (2019).

17. Gorodetskaya, I. V., Silva, T., Schmithüsen, H. \& Hirasawa, N. Atmospheric River Signatures in Radiosonde Profiles and Reanalyses at the Dronning Maud Land Coast, East Antarctica. Adv. Atmos. Sci. 37, 455-476 (2020).

18. Terpstra, A., Gorodetskaya, I. V. \& Sodemann, H. Linking Sub-Tropical Evaporation and Extreme Precipitation Over East Antarctica: An Atmospheric River Case Study. Journal of Geophysical Research: Atmospheres 126, e2020JD033617 (2021).

19. Gorodetskaya, I. V. et al. The role of atmospheric rivers in anomalous snow accumulation in East Antarctica. Geophysical Research Letters 41, 6199-6206 (2014).

20. Wille, J. D. et al. West Antarctic surface melt triggered by atmospheric rivers. Nat. Geosci. 12, 911-916 (2019).

21. Bozkurt, D., Rondanelli, R., Marín, J. C. \& Garreaud, R. Foehn Event Triggered by an Atmospheric River Underlies Record-Setting Temperature Along Continental Antarctica. Journal of Geophysical Research: Atmospheres 123, 3871-3892 (2018).

22. Francis, D., Mattingly, K. S., Temimi, M., Massom, R. \& Heil, P. On the crucial role of atmospheric rivers in the two major Weddell Polynya events in 1973 and 2017 in Antarctica. Sci Adv 6, eabc2695 (2020).

23. Wille, J. D. et al. Antarctic Atmospheric River Climatology and Precipitation Impacts. Journal of Geophysical Research: Atmospheres 126, e2020JD033788 (2021).

24. Agosta, C. et al. Estimation of the Antarctic surface mass balance using the regional climate model MAR (1979-2015) and identification of dominant processes. The Cryosphere 13, 281-296 (2019).

25. Qiao, G., Li, Y., Guo, S. \& Ye, W. Evolving Instability of the Scar Inlet Ice Shelf based on Sequential Landsat Images Spanning 2005-2018. Remote Sensing 12, 36 (2019).

26. Rott, H., Skvarca, P. \& Nagler, T. Rapid Collapse of Northern Larsen Ice Shelf, Antarctica. Science 271, 788-792 (1996).

27. Xu, M. et al. Dominant role of vertical air flows in the unprecedented warming on the Antarctic Peninsula in February 2020. Communications Earth \& Environment 2, 133 (2021).

28. Van Tricht, K. et al. Clouds enhance Greenland ice sheet meltwater runoff. Nature Communications 7, (2016). 
29. Banwell, A. F. et al. The 32-year record-high surface melt in 2019/2020 on the northern George VI Ice Shelf, Antarctic Peninsula. The Cryosphere 15, 909-925 (2021).

30. Vignon, É., Roussel, M.-L., Gorodetskaya, I. V., Genthon, C. \& Berne, A. Present and Future of Rainfall in Antarctica. Geophysical Research Letters n/a, e2020GL092281 (2021).

31. Costi, J. et al. Estimating surface melt and runoff on the Antarctic Peninsula using ERA-Interim reanalysis data. Antarctic Science 30, 379-393 (2018).

32. Hubbard, B. et al. Massive subsurface ice formed by refreezing of ice-shelf melt ponds. Nature Communications 7, 11897 (2016).

33. Doake, C. S. M., Corr, H. F. J., Rott, H., Skvarca, P. \& Young, N. W. Breakup and conditions for stability of the northern Larsen Ice Shelf, Antarctica. Nature 391, 778-780 (1998).

34. Holland, P. R. et al. Oceanic and atmospheric forcing of Larsen C Ice-Shelf thinning. The Cryosphere 9, 1005-1024 (2015).

35. Merino, N. et al. Impact of increasing antarctic glacial freshwater release on regional sea-ice cover in the Southern Ocean. Ocean Modelling 121, 76-89 (2018).

36. Etourneau, J. et al. Ocean temperature impact on ice shelf extent in the eastern Antarctic Peninsula. Nat Commun 10, 304 (2019).

37. Francis, D., Mattingly, K. S., Lhermitte, S., Temimi, M. \& Heil, P. Atmospheric extremes triggered the biggest calving event in more than 50 years at the Amery Ice shelf in September 2019. The Cryosphere Discussions 2020, 1-30 (2020).

38. Ralph, F. M. et al. A Scale to Characterize the Strength and Impacts of Atmospheric Rivers. Bulletin of the American Meteorological Society 100, 269-289 (2019).

39. Turton, J. V., Kirchgaessner, A., Ross, A. N., King, J. C. \& Kuipers Munneke, P. The influence of föhn winds on annual and seasonal surface melt on the Larsen C Ice Shelf, Antarctica. The Cryosphere Discussions 2020, 1-25 (2020).

40. Luckman, A. et al. Surface melt and ponding on Larsen C Ice Shelf and the impact of föhn winds. Antarctic Science 26, 625635 (2014).

41. Elvidge, A. D., Kuipers Munneke, P., King, J. C., Renfrew, I. A. \& Gilbert, E. Atmospheric Drivers of Melt on Larsen C Ice Shelf: Surface Energy Budget Regimes and the Impact of Foehn. Journal of Geophysical Research: Atmospheres 125, e2020JD032463 (2020).

42. van Wessem, J. M., Steger, C. R., Wever, N. \& van den Broeke, M. R. Modelling perennial firn aquifers in the Antarctic Peninsula (1979-2016). The Cryosphere Discussions 2020, 1-30 (2020).

43. Munneke, P. K., M. Ligtenberg, S. R., van den Broeke, M. R., van Angelen, J. H. \& Forster, R. R. Explaining the presence of perennial liquid water bodies in the firn of the Greenland Ice Sheet. Geophys. Res. Lett. 41, 476-483 (2014).

44. Gonzalez, S. \& Fortuny, D. How robust are the temperature trends on the Antarctic Peninsula? Antarctic Science 30, 322-328 (2018).

45. Turner, J. et al. Extreme Temperatures in the Antarctic. Journal of Climate 34, 2653-2668 (2021).

46. Sato, K., Inoue, J., Simmonds, I. \& Rudeva, I. Antarctic Peninsula warm winters influenced by Tasman Sea temperatures. Nature Communications 12, 1497 (2021).

47. Bevan, S., Luckman, A., Hendon, H. \& Wang, G. The 2020 Larsen C Ice Shelf surface melt is a 40-year record high. The Cryosphere 14, 3551-3564 (2020).

48. Hutchinson, K. et al. Water Mass Characteristics and Distribution Adjacent to Larsen C Ice Shelf, Antarctica. J. Geophys. Res. Oceans 125, (2020).

49. Hogg, A. E. \& Gudmundsson, G. H. Impacts of the Larsen-C Ice Shelf calving event. Nature Clim Change 7, 540-542 (2017).

50. Fürst, J. J. et al. The safety band of Antarctic ice shelves. Nature Clim Change 6, 479-482 (2016).

51. Lai, C.-Y. et al. Vulnerability of Antarctica's ice shelves to meltwater-driven fracture. Nature 584, 574-578 (2020).

52. Chyhareva, A., Krakovska, S. \& Pishniak, D. Climate projections over the Antarctic Peninsula region to the end of the $21 \mathrm{st}$ century. Part 1: cold temperature indices. UAJ 62-74 (2019) doi:10.33275/1727-7485.1(18).2019.131.

53. Siegert, M. et al. The Antarctic Peninsula Under a $1.5^{\circ} \mathrm{C}$ Global Warming Scenario. Front. Environ. Sci. 7, 102 (2019).

Page $12 / 21$ 
54. Espinoza, V., Waliser, D. E., Guan, B., Lavers, D. A. \& Ralph, F. M. Global Analysis of Climate Change Projection Effects on Atmospheric Rivers. Geophysical Research Letters 45, 4299-4308 (2018).

55. Zou, X., Bromwich, D. H., Montenegro, A., Wang, S.-H. \& Bai, L. Major Surface Melting over the Ross Ice Shelf Part I: Foehn Effect. Quarterly Journal of the Royal Meteorological Society n/a, (2021).

56. Zou, X., Bromwich, D. H., Nicolas, J. P., Montenegro, A. \& Wang, S. West Antarctic surface melt event of January 2016 facilitated by föhn warming. Quarterly Journal of the Royal Meteorological Society (2019) doi:10.1002/qj.3460.

57. Aster, R. C. et al. Swell-Triggered Seismicity at the Near-Front Damage Zone of the Ross Ice Shelf. Seismological Research Letters (2021) doi:10.1785/0220200478.

58. Bassis, J. N., Fricker, H. A., Coleman, R. \& Minster, J.-B. An investigation into the forces that drive ice-shelf rift propagation on the Amery Ice Shelf, East Antarctica. Journal of Glaciology 54, 17-27 (2008).

59. Zhou, Y. et al. Uncertainties in Atmospheric River Lifecycles by Detection Algorithms: Climatology and Variability. Journal of Geophysical Research: Atmospheres 126, e2020JD033711 (2021).

60. O'Brien, T. A. et al. Detection of atmospheric rivers with inline uncertainty quantification: TECA-BARD v1.0.1. Geoscientific Model Development 13, 6131-6148 (2020).

61. Gelaro, R. et al. The Modern-Era Retrospective Analysis for Research and Applications, Version 2 (MERRA-2). J. Climate 30, 5419-5454 (2017).

62. Fettweis, X. et al. Reconstructions of the 1900-2015 Greenland ice sheet surface mass balance using the regional climate MAR model. The Cryosphere 11, 1015-1033 (2017).

63. Gallée, H. \& Schayes, G. Development of a Three-Dimensional Meso-y Primitive Equation Model: Katabatic Winds Simulation in the Area of Terra Nova Bay, Antarctica. Monthly Weather Review 122, 671-685 (1994).

64. Ridder, K. D. \& Schayes, G. The IAGL Land Surface Model. Journal of Applied Meteorology 36, 167-182 (1997).

65. Brun, E., Martin, E., Simon, V., Gendre, C. \& Coleou, C. An Energy and Mass Model of Snow Cover Suitable for Operational Avalanche Forecasting. J. Glaciol. 35, 333-342 (1989).

66. Kittel, C. et al. Sensitivity of the current Antarctic surface mass balance to sea surface conditions using MAR. The Cryosphere 12, 3827-3839 (2018).

67. Donat-Magnin, M. et al. Interannual variability of summer surface mass balance and surface melting in the Amundsen sector, West Antarctica. The Cryosphere 14, 229-249 (2020).

68. Mottram, R. et al. What is the Surface Mass Balance of Antarctica? An Intercomparison of Regional Climate Model Estimates. The Cryosphere Discussions 2020, 1-42 (2020).

69. Datta, R. T. et al. Melting over the northeast Antarctic Peninsula (1999-2009): evaluation of a high-resolution regional climate model. The Cryosphere 12, 2901-2922 (2018).

70. Fettweis, X. et al. GrSMBMIP: Intercomparison of the modelled 1980-2012 surface mass balance over the Greenland Ice sheet. The Cryosphere Discussions 2020, 1-35 (2020).

71. Datta, R. T. et al. The Effect of Foehn-Induced Surface Melt on Firn Evolution Over the Northeast Antarctic Peninsula. Geophysical Research Letters 46, 3822-3831 (2019).

72. Jakobs, C. L. et al. A benchmark dataset of in situ Antarctic surface melt rates and energy balance. J. Glaciol. 66, 291-302 (2020).

73. Hersbach, H. et al. The ERA5 global reanalysis. Q.J.R. Meteorol. Soc. 146, 1999-2049 (2020).

74. Scambos, T. Images of Antarctic Ice Shelves. (2001) doi:10.7265/N5NC5Z4N.

75. Stuart, K. M. \& Long, D. G. Iceberg size and orientation estimation using SeaWinds. Cold Regions Science and Technology 69, 39-51 (2011).

76. Picard, G. \& Fily, M. Surface melting observations in Antarctica by microwave radiometers: Correcting 26-year time series from changes in acquisition hours. Remote Sensing of Environment 104, 325-336 (2006).

77. Moussavi, M. et al. Antarctic Supraglacial Lake Detection Using Landsat 8 and Sentinel-2 Imagery: Towards Continental Generation of Lake Volumes. Remote Sensing 12, (2020).

Page $13 / 21$ 


\section{Tables}

Table 1: AR extremes associated with calving events and collapses. Extreme events occurring between AR beginning and ending dates are denoted as "True", whereas "False" refers to the lack of co-occurring extreme event. Temperature, melt, runoff (swell height) values exceeding the $95^{\text {th }}$ ( $85^{\text {th }}$ respectively) percentile of summer values are considered. Significant sea ice removal is when values exceed + 2 sigma. Lines in italics are ARs retrieved in 2002 with the IWV script only. Bold are ARs associated with Larsen A and Larsen B collapses.

\begin{tabular}{|c|c|c|c|c|c|c|c|c|c|}
\hline AR begin & AR end & $\begin{array}{l}\text { Date } \\
\text { Collapse }\end{array}$ & $\begin{array}{l}\text { Cumulated } \\
\text { IVT }\end{array}$ & Temperature & Melt & Runoff & $\begin{array}{l}\text { Sea } \\
\text { ice }\end{array}$ & Swells & Observations \\
\hline 24/01/1995 & 25/01/1995 & 25/01/1995 & 3987 & True & True & True & True & True & Collapse \\
\hline $25 / 02 / 2000$ & $25 / 02 / 2000$ & $27 / 02 / 2000$ & 555 & True & False & True & False & False & \\
\hline $31 / 12 / 2001$ & 02/01/2002 & 06/01/2002 & 7421 & True & False & True & False & True & \\
\hline $04 / 02 / 2002$ & $05 / 02 / 2002$ & $08 / 02 / 2002$ & 1878 & True & False & True & $\begin{array}{l}\text { No } \\
\text { more } \\
\text { SI }\end{array}$ & False & $I W V$ script \\
\hline 18/02/2002 & $20 / 02 / 2002$ & 23/02/2002 & 3982 & True & False & True & $\begin{array}{l}\text { No } \\
\text { more } \\
S I\end{array}$ & False & $I W V$ script \\
\hline $25 / 02 / 2002$ & $27 / 02 / 2002$ & 02/03/2002 & 5602 & True & True & True & $\begin{array}{l}\text { No } \\
\text { more } \\
\text { SI }\end{array}$ & True & Collapse \\
\hline $28 / 10 / 2002$ & 29/10/2002 & 29/10/2002 & 4585 & False & False & False & False & False & \\
\hline $13 / 01 / 2003$ & $13 / 01 / 2003$ & $18 / 01 / 2003$ & 391 & True & False & True & True & False & \\
\hline $19 / 02 / 2003$ & $19 / 02 / 2003$ & $23 / 02 / 2003$ & 919 & True & False & True & True & True & \\
\hline $18 / 04 / 2003$ & $20 / 04 / 2003$ & $18 / 04 / 2003$ & 414 & False & False & False & False & False & \\
\hline 03/01/2005 & 05/01/2005 & 03/01/2005 & 1058 & True & True & True & True & True & \\
\hline 09/02/2005 & $10 / 02 / 2005$ & $11 / 02 / 2005$ & 6387 & True & True & True & False & False & \\
\hline 29/12/2005 & $30 / 12 / 2005$ & $01 / 01 / 2006$ & 3752 & True & False & True & False & False & \\
\hline $18 / 01 / 2006$ & $18 / 01 / 2006$ & $20 / 01 / 2006$ & 355 & True & True & True & True & False & \\
\hline 06/02/2006 & $08 / 02 / 2006$ & $11 / 02 / 2006$ & 2838 & True & True & True & True & False & \\
\hline $26 / 11 / 2008$ & $27 / 11 / 2008$ & $30 / 11 / 2008$ & 4370 & True & False & True & False & False & \\
\hline 05/07/2017 & 06/07/2017 & $10 / 07 / 2017$ & 5066 & False & False & False & False & False & Winter event \\
\hline
\end{tabular}

\section{Figures}



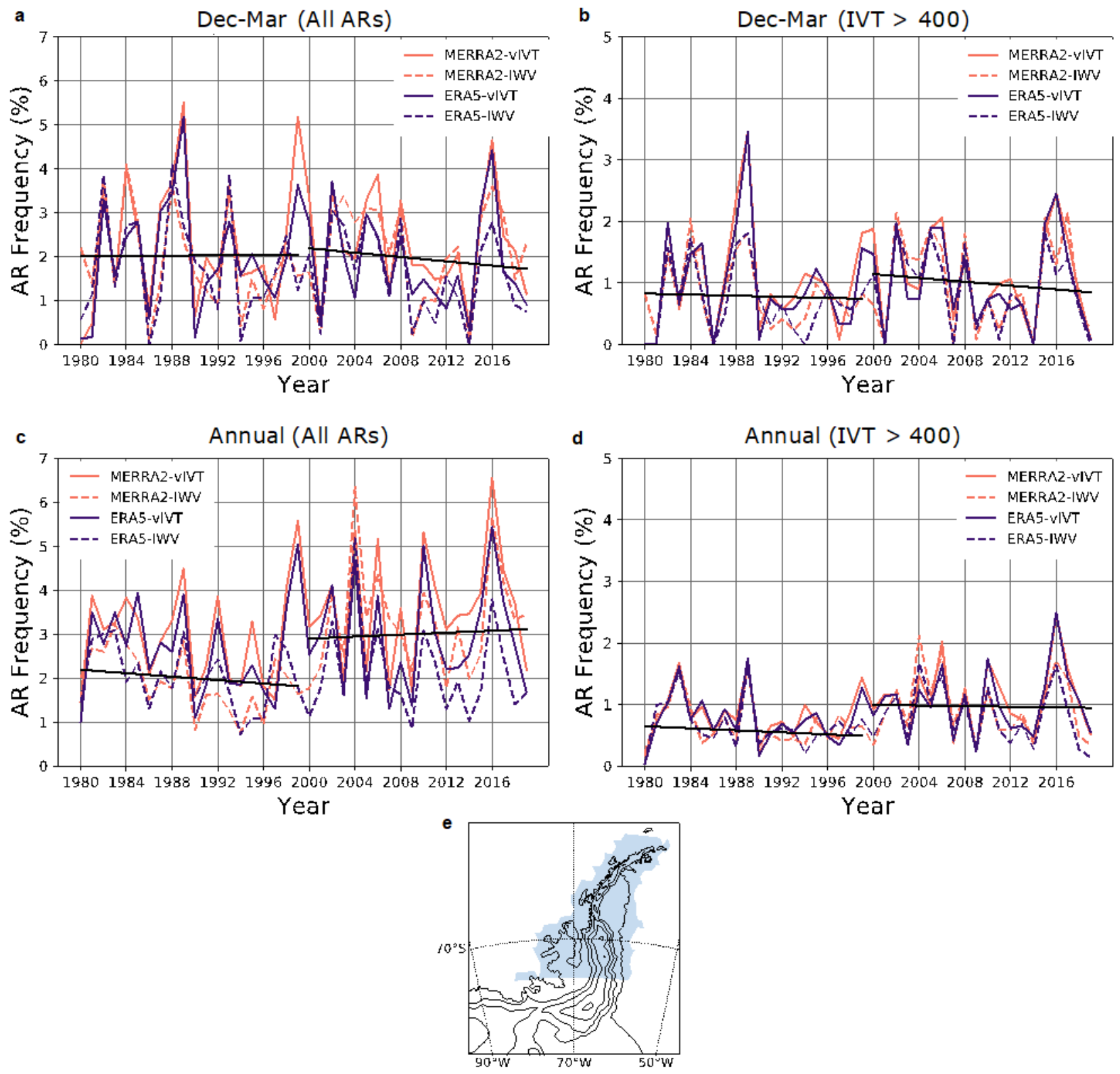

\section{Figure 1}

Annual AR frequency and trends. Frequency of AR landfalls on the Antarctica Peninsula for $a, b$ December - March and c, $d$ yearly according to the VIVT and IWV AR detections schemes when applied to MERRA-2 and ERA-5 reanalysis. $b, d$ represent the AR frequency when all AR landfalls with a maximum IVT below $400 \mathrm{~kg} \mathrm{~m}-1 \mathrm{~s}-1$ are removed from the record. The year in a and $b$ refers to the austral summer of December, January, February, March (i.e., the austral summer of 1988-1989 is referenced as 1989 in the plots). An AR landfall is counted if an AR shape touches the region highlighted in e. 


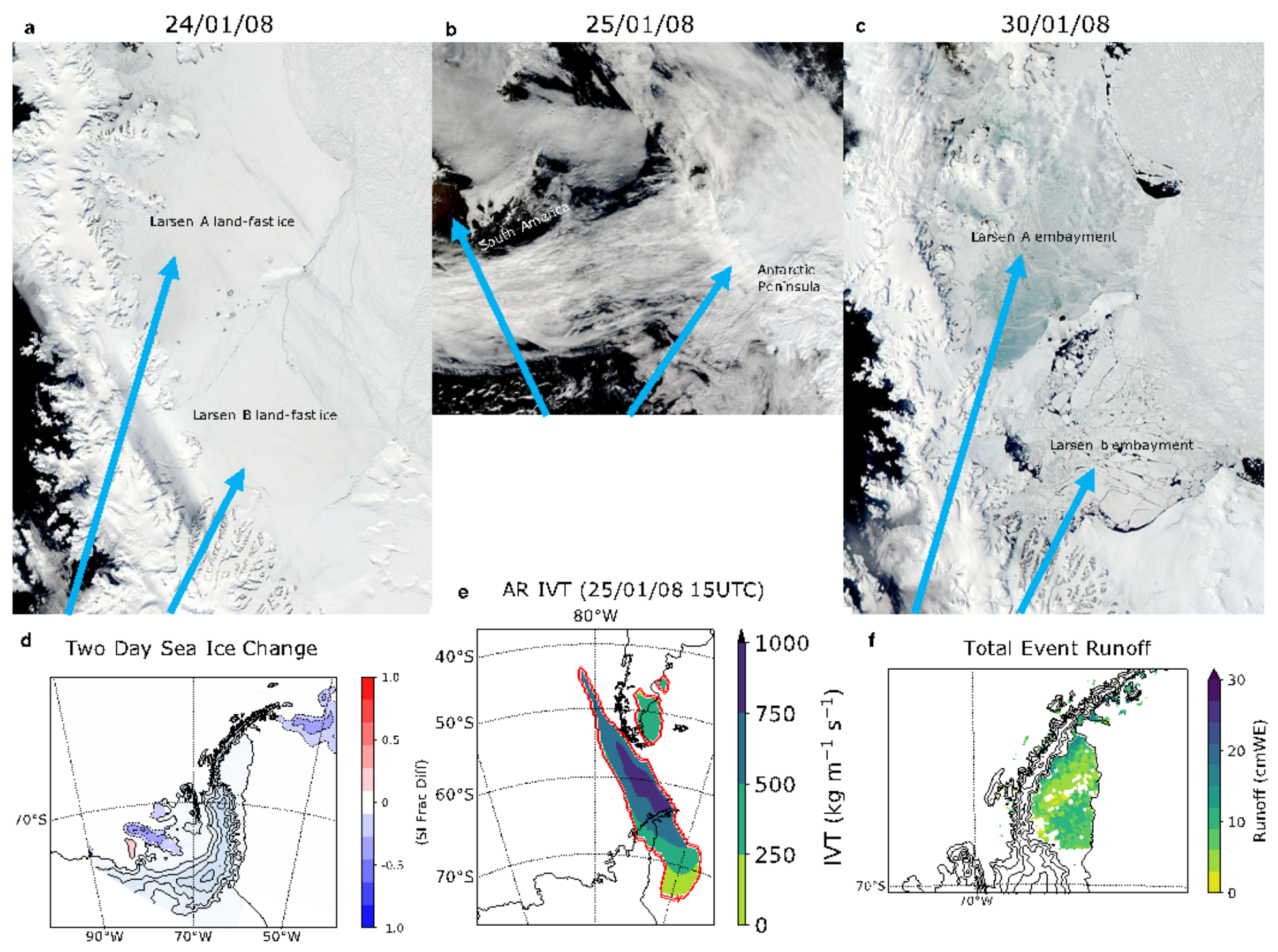

Figure 2

Overview of January 25th, 2008, AR over the AP. MODIS satellite imagery from a 24/01/08 and c 30/01/08 showing the land-fast ice and sea ice decay after the passing of an AR as seen in b 25/01/08. $d$ The two-day sea ice change centered on the AR occurrence from 25/01/08 00 UTC. e the shape and intensity of the detected AR on 25/01/08 15 UTC. f The total runoff that occurred from 25/01/08 - 30/01/08. 

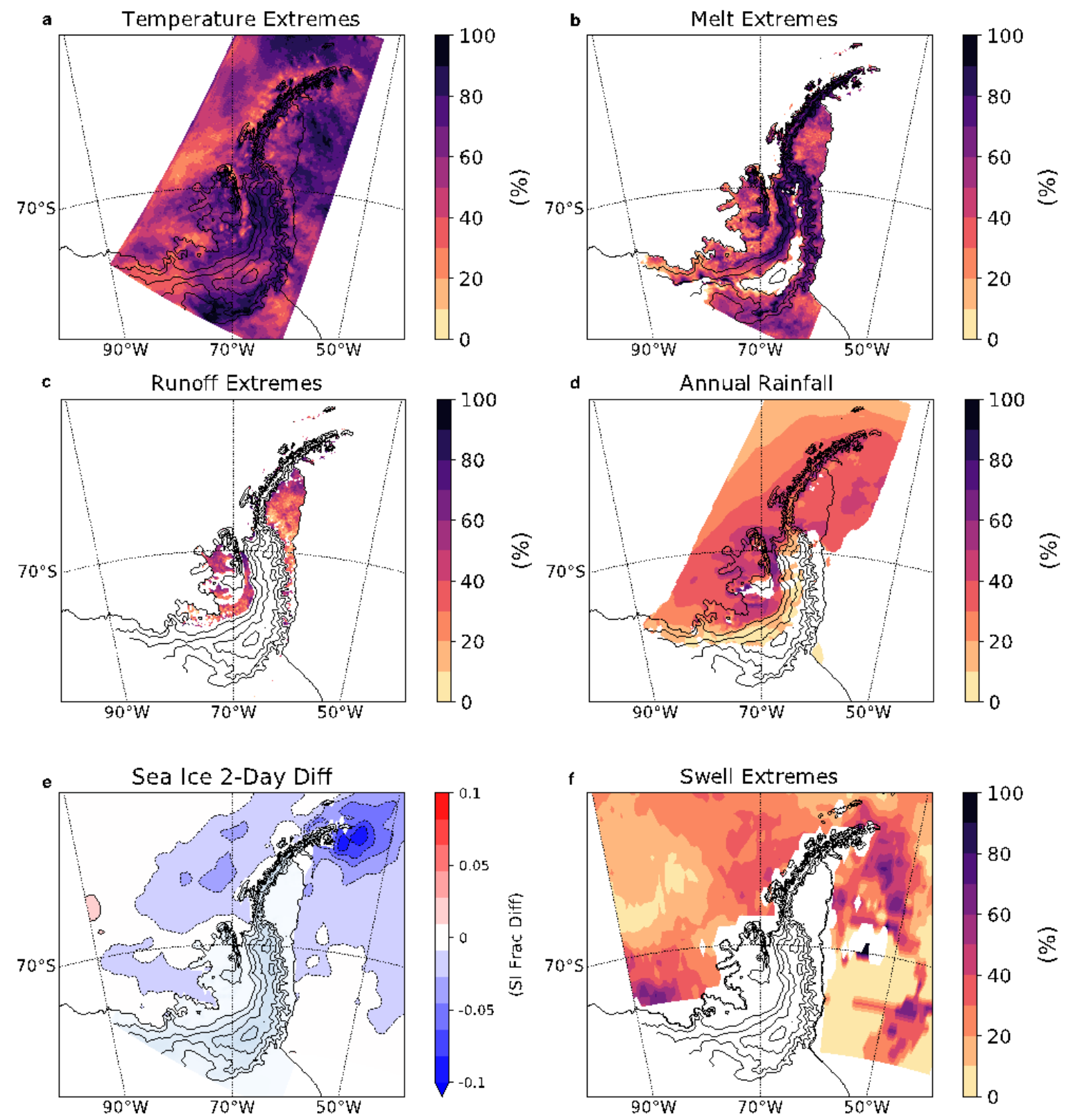

Figure 3

Relationship between ice shelf destabilizing extremes and ARs. The percentage of MAR summer a $2 \mathrm{~m}$ temperature occurrences $\mathrm{b}$ surface melt, and c runoff at or above the 99.9th percentile of the 1980-2019 monthly mean climatology that occurred within 24 hours before and after an AR landfall on the AP. d Percentage of total annual rainfall from 1980-2019 associated with AR landfalls. e The composite two-day sea ice fraction difference for annual AR landfalls with a maximum IVT at or above $400 \mathrm{~kg} \mathrm{~m}-1 \mathrm{~s}-1$ ( $\mathrm{n}=$ 357). $f$ Percentage of annual swells at or above the 99.9th percentile of the 1980-2019 monthly mean climatology associated with AR landfalls. 


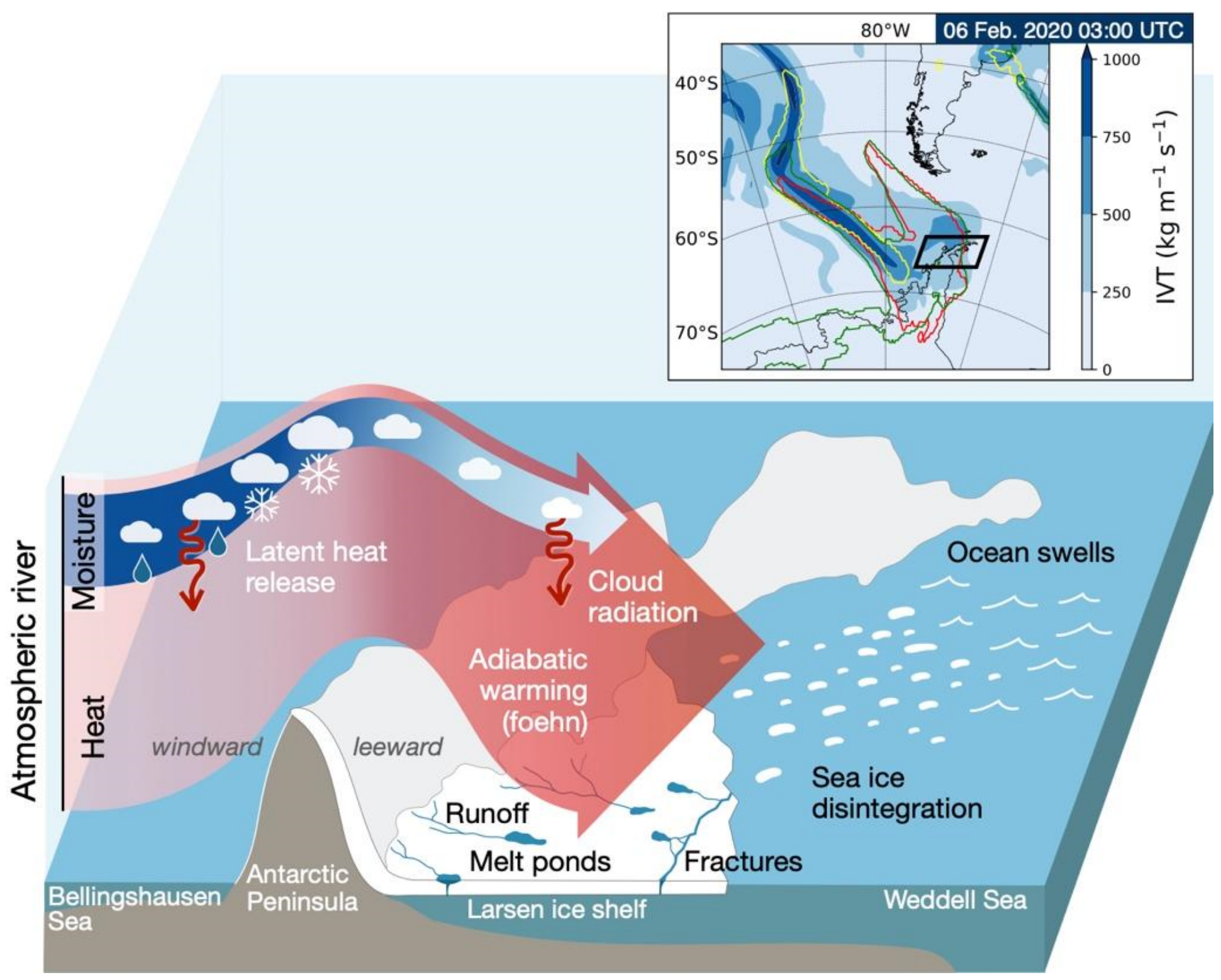

\section{Figure 4}

Illustration of an AR landfall on the AP. An illustration of a typical intense atmospheric river over the northern Antarctic Peninsula and the associated observed meteorological features and impacts consequential to ice-shelf stability. Also, an example of a detected AR landfall on Feb. 6th, 2020, with the corresponding IVT values. The yellow, red, and green outlines are the shape of the AR as determined by the VIVT AR detection scheme, IWV AR detection scheme, and the original Antarctic AR detection algorithm respectively 17,19 (Gorodetskaya et al. 2014, 2020). 
a

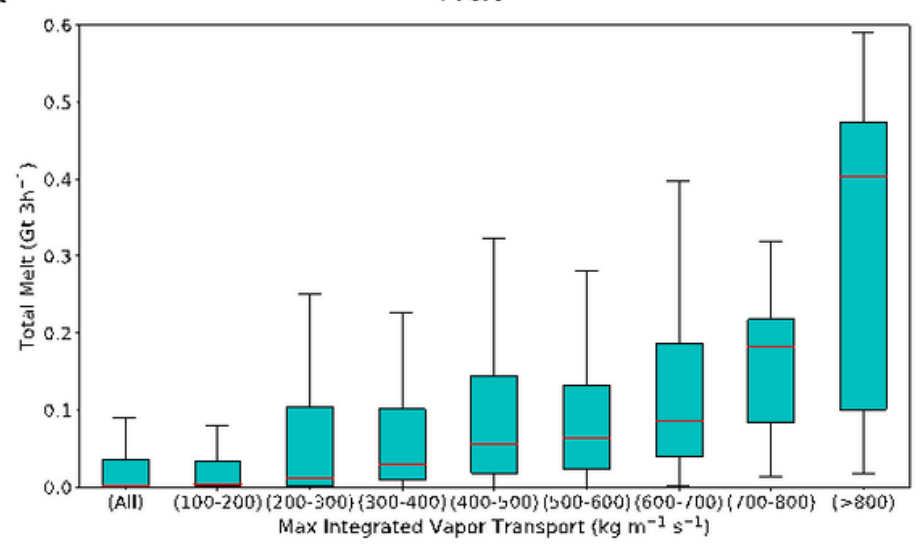

b

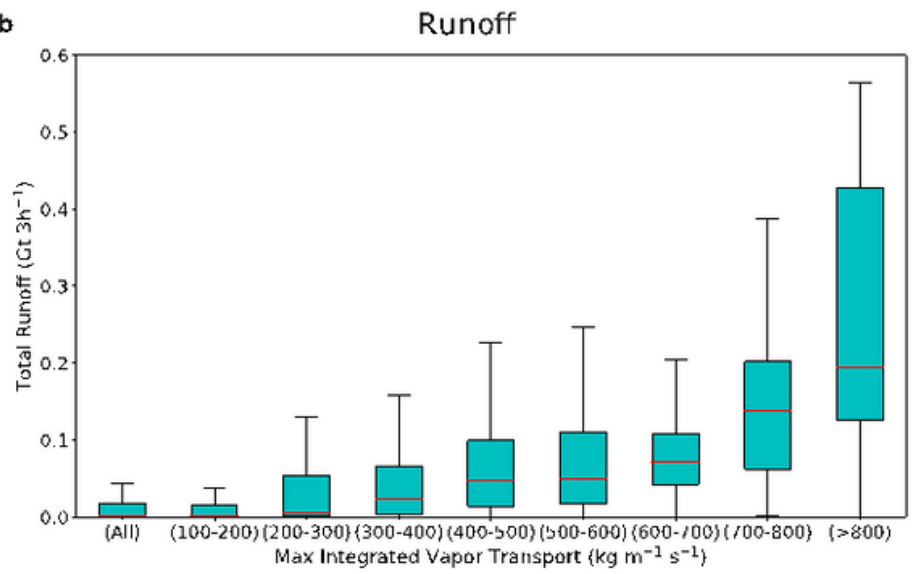

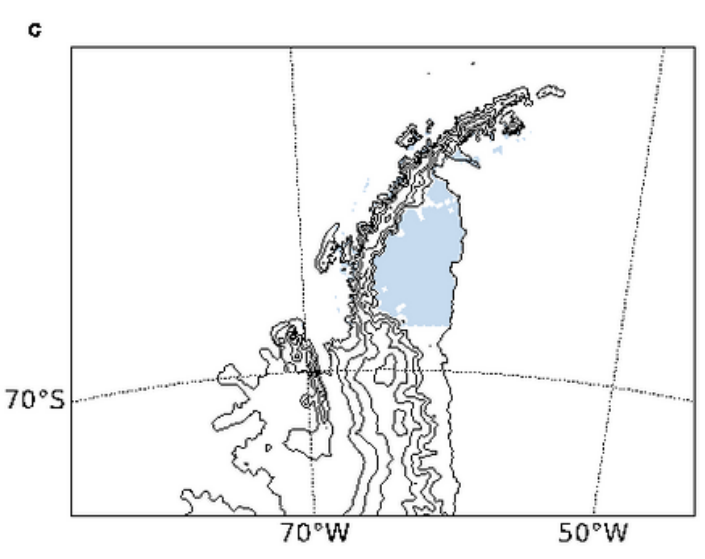

Figure 5

The relationship between AR intensity and melt/runoff intensity. The maximum integrated vapor transport (IVT) upon landfall for each detected AR timestep and the corresponding 3-hourly cumulative a surface melt and b runoff over $c$ the area shaded in blue using MERRA-2 for IVT and MAR for surface melt and runoff. The most common IVT intensity was 300-400 kg m-1 s-1 ( $\mathrm{n}=273$ ), while the least common IVT intensity was $>800 \mathrm{~kg} \mathrm{~m}-1 \mathrm{~s}-1(n=14)$ over the December-March period. The area of the blue shaded region is $\sim 91,400 \mathrm{~km} 2$ 


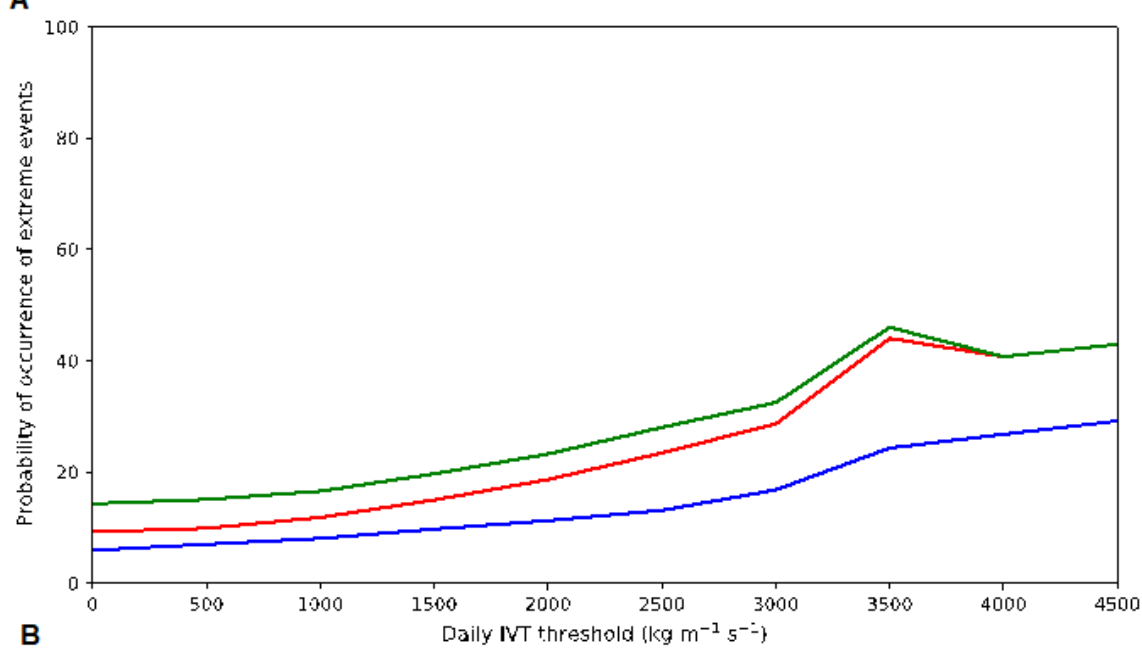

C
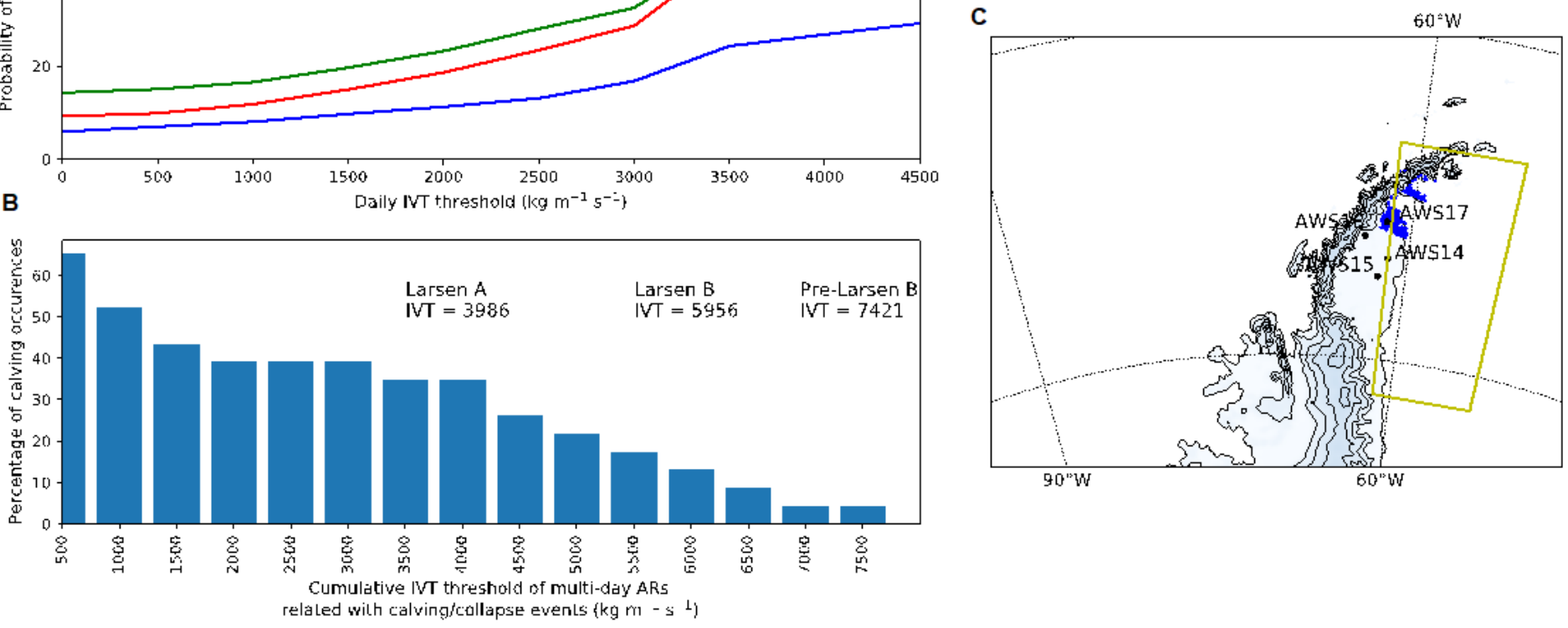

$90 " \mathrm{~W}$

$60^{\prime \prime} W$

Figure 6

Percentage of occurrence of extreme events according to IVT threshold. a Probability of occurrence of a daily temperature, melt or runoff value exceeding the $95 \%$ percentile summer (NDJFM) values (blue line and area) at one location of the area highlighted by the blue dots in c which are located below $200 \mathrm{~m}$ asl and over the ice mask of the MAR. The line is the mean occurrence for all the points, and the area is the lowest and highest percentages of occurrence (i.e. the 5-95\% interval) considering occurrences at each individual point. The red line and area consider the same parameters as the blue line and area, but also includes the occurrence of two-day sea ice removal exceeding $2 \%(\mathrm{SIC}>0.02)$ in the region described in yellow box. SIC = 0.02 represents the 1 sigma value of all the daily SIC variations observed over 40 years. The green line and area consider the same parameters as the red line, but also includes the occurrence of swell above the 85th percentile (1980-2019) within the yellow box in c. b The histogram represents the \% of occurrence collapse / calving occurring after an AR event as a function of a IVT threshold based on the cumulative values of each continuous multi-day event. This includes 13 calving events plus the Larsen A collapse on January 25, 1995 and the winter calving event of the Larsen C during July 10-12, 2017. The pre-Larsen B refers a large calving event occurring on January 6,2002 , and the Larsen B collapse refers to the final collapse after March 2, 2002. 
a

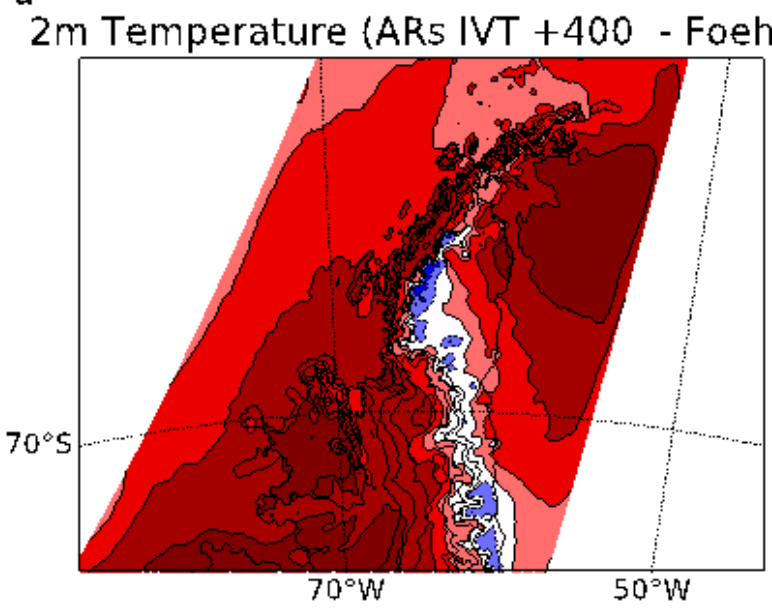

c SHF (ARs IVT $+400-$ Foehn)

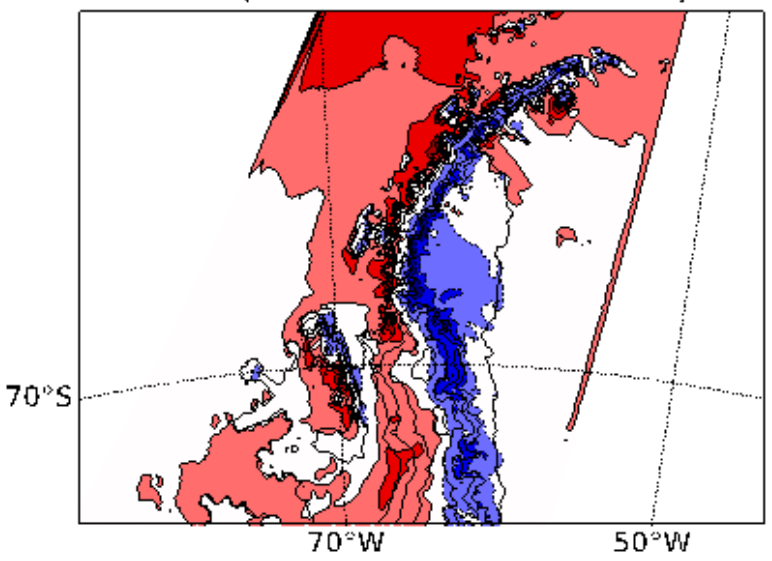

b
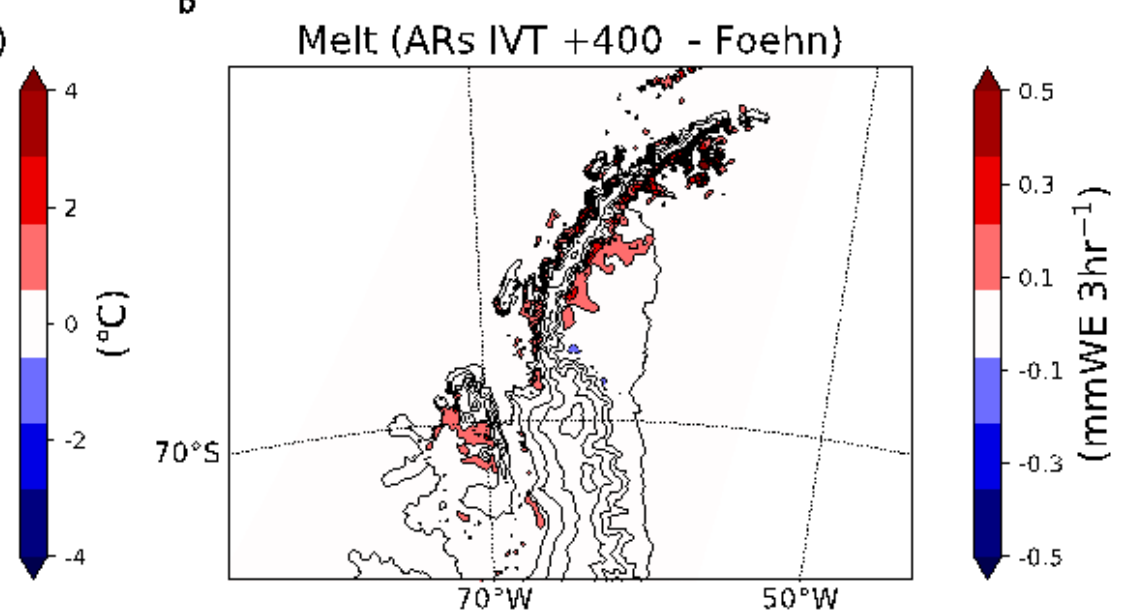

d

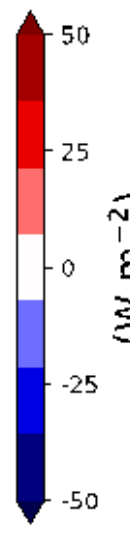

LWD (ARs IVT +400 - Foehn)

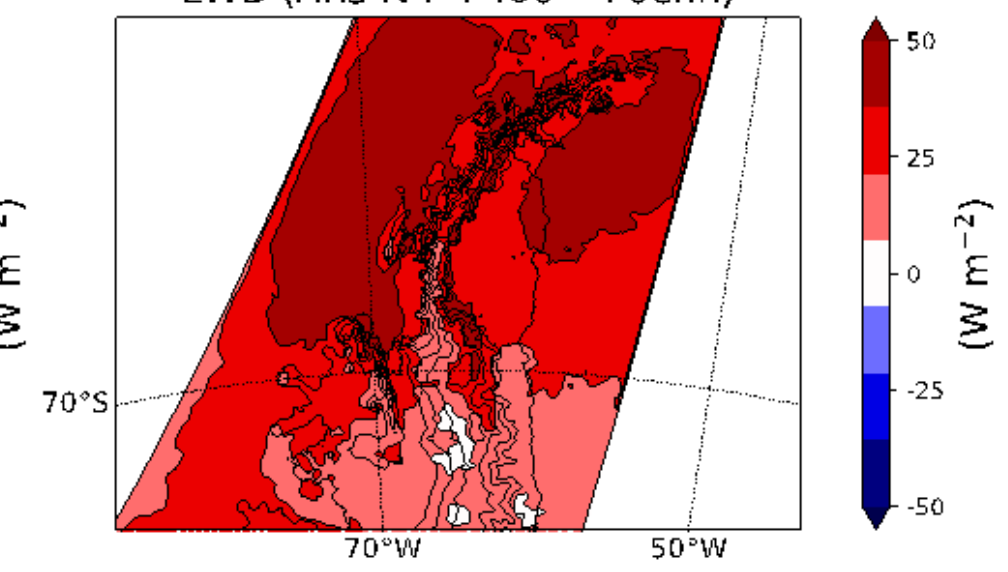

Figure 7

Differences between standalone ARs and foehn winds. The difference between anomalies associated with AR landfalls with an IVT above $400 \mathrm{~kg} \mathrm{~m}-1 \mathrm{~s}-1$ and foehn events according to the algorithm in Turton et al. 2018 for MAR a $2 \mathrm{~m}$ temperature, b surface melting, c sensible heat flux, and d downward longwave radiation from 2009-2012.

\section{Supplementary Files}

This is a list of supplementary files associated with this preprint. Click to download.

- WilleetalSMnature.pdf 